\title{
中国东部裂谷系地幔脱气的氦同位素证据 *
}

\author{
杜建国 \\ (中国科学院兰州地质研究所气体地球化学国家重点实验室, 兰州 730000)
}

\section{关键词地股脱气、昰同位素、裂谷系}

大气中发现的放射性成因 ${ }^{40} \mathrm{Ar}$ 和 ${ }^{4} \mathrm{He}$ 被认为是地球内部放射性元素 (如铀、针等) 自然衰 变的产物经地球脱气进人大气圈的 ${ }^{[1,2]}$. 稀有气体同位素组成及其相对比值是地球脱气理论 和地幔地球化学演化很重要的地球化学指标, 据此提出了地球脱气的连续性模式和突变性模 式 ${ }^{[3,4]}$. 地球脱气在时间上有突变性, 在地理位置或大地构造位置上具不均匀性. 大陆裂谷、 大洋中脊、火山岛孤是地球脱气通量最大的地带. 地球裂谷带不仅有大量挥发分从地球深部 向外逃逸, 而且有大量地球深部岩浆和热向上逸出 ${ }^{[5]}$. 本文根据三十多个氦同位素数据和其 他地球化学、地质学资料来讨论中国东部大陆裂谷地幔的脱气.

\section{1 样品采集与分析}

32 个天然气样采自中国东部大陆裂谷内的三水盆地、东台凹陷、东幞凹陷、黄骓坳陷、下 辽河盆地、万金塔构造等地区. 气样容器为两头带闹的金属瓶, 可承压力 150 个大气压, 容积 约为 0.7 或 $1 \mathrm{~L}$. 氦同位素组成用 VG-5400 型质谱计测定, 测量误差为 $1 \%$. 样品的氦同位素 组成见表 1.

\section{2 讨 论}

大量地球物理探测资料和地质资料表明中国大陆东部有一裂谷系. 它形成于中 - 新生 代, NNE-SSW 延伸约 $4000 \mathrm{~km}$, 宽约 $300-400 \mathrm{~km}$. 裂谷内由于地幔上隆使地壳变薄 $(30-32 \mathrm{~km})$, 在裂谷系东西邻近山区地壳厚度较厚 $(35-43 \mathrm{~km})$, 并且西部地壳厚度大于东 部. 裂谷系中形成了一系列雁行式排列的中、新生代沉积盆地和若干切割莫霍面的深大断裂. 详细的地质、地球物理资料参见文献[6-10].

中国东部大陆裂谷中有丰富的天然气资源. 部分天然气氦含量较高 $(>0.1 \%)$, 氦同位素 比值 $\left({ }^{3} \mathrm{He} /{ }^{4} \mathrm{He}\right)$ 分布于 $2.23 \times 10^{-7}-6.42 \times 10^{-6}$ 的范围内 (表 1). 赋存于天然气中的氦以气 态单原子存在, 在地质体中的分布既受天然气成储地质条件的控制, 也受地球深部物质运动 和深大断裂的影响. 统计结果表明中国东部大陆裂谷系内天然气中氦的浓度与其他非烃气体 $\left(\mathrm{CO}_{2} \cdot \mathrm{N}_{2}\right)$ 的浓度成正比, 而且高含氦天然气多数分布于深大断裂带附近或新生代基性 - 超基 性岩浆活动地区. 如三水盆地水深 9 、水深 24 井、苏北黄浅 1 、黄浅 14 井,下辽河界 3 井等就

1993-11-18 收稿, 1994-01-12 收修改稿.

* 国家自然科学基金资助项目. 
表 1 中国东部大陆裂谷天然气中氦含量及氦同位素组成

\begin{tabular}{|c|c|c|c|c|c|c|c|c|c|}
\hline 地 区 & 井 号 & 储层时代 & $\mathrm{He}(\%)$ & $\begin{array}{l}{ }^{3} \mathrm{He} /{ }^{4} \mathrm{He} \\
\left(\times 10^{-6}\right)\end{array}$ & 地 区 & 井 号 & 储层时代 & $\mathrm{He}(\%)$ & $\begin{array}{l}{ }^{3} \mathrm{He} /{ }^{4} \mathrm{He} \\
\left(\times 10^{-6}\right)\end{array}$ \\
\hline$\equiv$ & 水深 3 & $\mathrm{E}_{1-2} \mathrm{~b}$ & 0.3 & 5.76 & 下近河 ${ }^{[11]}$ & 界 3 & $\mathrm{~J}$ & 0.1 & 5.5 \\
\hline 水 & 宝 1 & $E_{1-2} b$ & & 1.60 & & & & & \\
\hline 盆 & 水深 17 & $E_{1-2} b$ & 0.014 & 1.71 & & 纪 1 & Ef & & 6.42 \\
\hline \multirow[t]{7}{*}{ 地 } & 水深 44 & $E_{1-2} b$ & 0.11 & 6.26 & 东 ${ }^{[1]}$ & 黄浅 1 & $\mathrm{Ny}$ & 1.20 & 4.90 \\
\hline & 水深 9 & $E_{1-2} b$ & 0.008 & 6.02 & 台 & 黄浅 14 & $\mathrm{Ny}$ & 1.34 & 3.71 \\
\hline & 水深 24 & $\mathrm{E}_{1-2} \mathrm{~b}$ & & 6.39 & 凹 & 黄验 1 & $P_{1} q$ & & 4.90 \\
\hline & 水深 12 & $E_{1-2} b$ & 0.245 & 4.08 & 降 & 苏泰 174 & $P_{3} w$ & & 5,54 \\
\hline & 南 20 & $E_{1-2} b$ & 0.145 & 2.45 & & 永 7 & Ed & & $7.45^{a)}$ \\
\hline & 5 排 1 & $\mathrm{E}_{1 \cdot 2 \mathrm{~b}} \mathrm{~b}$ & & 2.90 & & & & & \\
\hline & & & & & & 东 2841 & $\mathrm{Nm}$ & & $7.25^{\mathrm{a})}$ \\
\hline 东 & 文 23 & $\mathrm{Es}_{4}$ & & $2.23^{\mathrm{a})}$ & & 板中 14 & $E s_{1}$ & & $2.82^{a)}$ \\
\hline 洪 & 文 108 & $\mathrm{Es}_{4}$ & & $3.28^{\mathrm{a})}$ & & 管 187 & $\mathrm{Es}_{3}$ & $310^{\mathrm{c})}$ & $4.32^{\mathrm{a})}$ \\
\hline 凹 & 白 10 & $\mathrm{Es}_{3}$ & & $8.62^{\mathrm{a})}$ & 黄b) & 港深 7 & $E s_{1}$ & $15^{c)}$ & $4.85^{\mathrm{a})}$ \\
\hline \multirow[t]{2}{*}{ 陷 } & 开 28 & $\mathrm{Es}_{3}$ & & $8.48^{\mathrm{a})}$ & 骓 & 港 151 & $\mathrm{Es}_{1}$ & & 5.05 \\
\hline & & & & & 场 & 新 8-8 & $\mathrm{Nm}$ & & 3.04 \\
\hline $5^{(11)}$ & 万 2 & $\mathrm{Kq}$ & & 7.01 & 陷 & 西 10-7 & $\mathrm{Ng}$ & & 3.81 \\
\hline 金 & 万 5 & $\mathrm{Kq}$ & & 6.31 & & 西 46-6 & $\mathrm{Nm}$ & & 1.48 \\
\hline 塔 & 万 6 & $\mathrm{Kq}$ & & 7.21 & & 西 9-12 & $\mathrm{Nm}$ & $420^{c)}$ & 2.85 \\
\hline
\end{tabular}

a) $\times 10^{-7}$, b) 杨池银, 硕士论文, 1990; c) 单位: ppm.

是位于古火山口附近或邻近深大断裂带. 天然气氦同位素地球化学特征主要为 ${ }^{3} \mathrm{He} /{ }^{4} \mathrm{He}$ 值高 的天然气也与深大断裂、火山活动有关, 同时与地幔隆起幅度有关. 地幔隆起区, 如三水盆 地、东台凹陷、万金塔地区 (约在北纬 $23^{\circ}, 33^{\circ}, 43^{\circ}$ ) ${ }^{[9,10]}$ 天然气的 ${ }^{3} \mathrm{He} /{ }^{4} \mathrm{He}$ 值和 ${ }^{4} \mathrm{He} /{ }^{20} \mathrm{Ne}$ 值都 较高.

中国东部大陆裂谷系与其他裂谷系 ${ }^{[5]}$ 类似, 发育有源于上地幔的岩浆岩, 古火山活动强 烈. 地壳下面存在有异常地幔层, 地壳被上隆的地幔拉伸减薄, 在这个过程中有大量流体向 上逸出. 研究表明天然气中氦的来源主要有三种: (1) 地幔来源的氦, 其 ${ }^{3} \mathrm{He} /{ }^{4} \mathrm{He}$ 值平均为 $1.1 \times 10^{-5}$; (2) 地壳来源的氦, 其 ${ }^{3} \mathrm{He} /{ }^{4} \mathrm{He}$ 值平均为 $2 \times 10^{-8}$; (3) 大气圈来源的氦, 其 ${ }^{3} \mathrm{He} /{ }^{4} \mathrm{He}$ 值在对流层中为 $1.4 \times 10^{-6[12-15]}$. 璌同位素地球化学研究表明中国东部裂谷系中天然气中的 氦部分源于地幔 ${ }^{[11,12,16] .}$

根据天然气中非烃组分及其同位素相对比值可以确定天然气中氦的来源. 东部大陆裂谷 天然气的 ${ }^{40} \mathrm{Ar} /{ }^{36} \mathrm{Ar},{ }^{4} \mathrm{He} /{ }^{20} \mathrm{Ne}, \mathrm{He} / \mathrm{Ar}, \mathrm{N}_{2} / \mathrm{He}$ 值与大气中的截然不同 (表 2). 大气中组分进人

表 2 中国东部天然气和大气的若干地球化学参数

\begin{tabular}{c|cccc}
\hline 参 数 & ${ }^{40} \mathrm{Ar} /{ }^{36} \mathrm{Ar}$ & ${ }^{4} \mathrm{He} /{ }^{20} \mathrm{Ne}$ & $\mathrm{He} / \mathrm{Ar}$ & $\mathrm{N}_{2} / \mathrm{He}$ \\
\hline 天然乞 & $450-2000$ & $710-8930$ & $<10^{-3}-28$ & $<10^{-4}-11$ \\
大 气 & 295.5 & 0.32 & $5.7 \times 10^{-5}$ & $1.7 \times 10^{-5}$ \\
\hline
\end{tabular}

岩石圈的主要途径有: (1)沉积过程中 由沉积介质中进人沉积物; (2) 大气降 水下渗过程中带人岩石中; (3) 气体扩 散进人近地表的岩石. 由于 ${ }^{20} \mathrm{Ne}$ 的溶 解度较 ${ }^{4} \mathrm{He}$ 的大, 并且天然气的 ${ }^{4} \mathrm{He} /{ }^{20} \mathrm{Ne}$ 值远大于空气, 所以可以排除大气氦通过上述三种过程进人岩石圈, 混人天然气藏 中. 结合其他指标, 判断天然气中大气来源的氦可以忽略不计, 而主要是源于地幔及地壳. 
因此, 可以用二元混合模式估算天然气中地幔来源氦所占比例:

$$
a=\frac{R_{\mathrm{s}}-R_{\mathrm{c}}}{R_{\mathrm{m}}-E_{\mathrm{c}}} \times 100 \%,
$$

式中 $a$ 为幔源氦占天然气中氦的比例, $R_{\mathrm{s}}, R_{\mathrm{c}}, R_{\mathrm{m}}$ 分别代表样品的、地壳来源的和地幔来源 氦的 ${ }^{3} \mathrm{He} /{ }^{4} \mathrm{He}$ 值. 根据表 1 中的氦同位素比值利用 (1) 式估算东部裂谷系内天然气中幔源氦 占 $10-60 \%$ 以上. 东兴凹陷和黄骅㘬陷一些富烃天然气中幔源氦占的比例偏小, 可能与华 北地台放射性元素比其他地区高有关. 利用 ${ }^{3} \mathrm{He} /{ }^{4} \mathrm{He}$ 值估算的裂谷系内大地热流值 $\left(59.7-82.6 \mathrm{~W} \cdot \mathrm{m}^{-2}\right)^{[12]}$ 也能说明这一点. 在华北地台多数天然气田地壳放射性热对大地 热流值的贡献比其他地区的大. 地热研究也表明华北地台平均大地热流值在隆起区较凹陷区 低, 地幔来源热的贡献约为总量的 $20-38 \%{ }^{[10]}$. 假若在大陆裂谷内地幔氦的逃逸通量是一 致的, 则由于地壳来源氦的相对增大可以使 ${ }^{3} \mathrm{He} /{ }^{4} \mathrm{He}$ 值及地幔来源热占大地热流总量的比例都 降低. 因此, 这意味着研究区地幔氦向上逃逸的量是相当可观的.

中国东部大陆裂谷系内天然气形成聚集时间一般为早第三纪晚期一晚第三纪. 因此, 可 以推断经地幔脱气进人天然气藏中的氦应该是晚第三纪以来逐渐聚集的. 氦的扩散、渗透性 强, 气藏中较高浓度的氦是动态平衡的结果, 这意味着自晚第三纪以来地幔脱气一直在进 行, 并且脱气通量较大. 裂谷内新生代基性 - 超基性火山岩的广泛分布也是这一论点的佐证. 上述证据, 尤其是氦同位素地球化学资料, 表明中国东部大陆裂谷系地幔自晚第三纪以来处 于强脱气状态.

致谢本文在完成过程中曾得到欧阳自远院士、王永法、王先彬和谢鸿森教授的帮 助, 表示哀心的感谢.

\section{参 考文献}

[1] Tatel, H. E., Geophys, Res., 1950, 55:329--336.

[2] Schillibeer, H. A., Russel, R. D., Geochim. Cosmochim. Acta, 1955, 8:16-21.

[3] Schwartzman, D. W., in Adva. Earth Plant. Sci. (eds. Alexander, Jr. E. C., Ozima, M.), Japan Scientific Societies Press, 1978, 1985-191.

[4] Hart, R., Hogan, L., Adva. Earth Plant. Sci. (eds. Alexander, Jr. E. C., Ozima, M.), Japan Scientific Societies Press., 1978, 192-206.

[ 5] 陈家振、高其斋、毛继国 (译), 地球裂谷带,地震出版社, 北京, 1982 .

[6] 马杏垭、宿 俭, 现代地壳运动研究 (1),地震出版社, 北京, 1985, 5-16.

[ 7] 邓晋福、赵海玲, 中国上地涭特征与动力学论文集,地震出版社, 北京, 1990, 8-13.

[8]丁国瑜主编, 中国岩石圈动力学概论,科学出版社, 北京, 1991.

[9] 魏斯高等, 中国东部大陆边缘地带的岩石圈结构与动力学,科学出版社, 北京, 1990.

[10] 国家地震局《深部物探成果》编写组, 中国地壳上地地球物理探测成果, 地震出版社, 北京 1986.

[11] 徐永昌等, 中国科学, B 辑, 1990, (4):409-418.

[12] Du, J., Chinese J. Geochem., 1992, 11(3): 237-243.

[13] Mamyrin, B. A., Tolstikhin, L. N., Helium Isolopes in Nature, Elsevier Sci. Publ., B. V., 1984.

[14] 杜建国, 地质地球化学, 1989, (4) : 56-59.

[15]王先林, 稀有气体同位素地球化学和宇宙化学,科学出版社, 北京, 1989.

[16] 徐永昌等著, 天然气形成机理及应用, 第十二章, 科学出版社, 北京, 1994 (待发表). 